\title{
KAJIAN DAERAH RAWAN GEMPA DI BULUKUMBA SULAWESI SELATAN
}

\author{
Muhammad Altin Massinai, Saaduddin, Muhammad Fawzy Ismullah Massinai \\ Program Studi Geofisika, Fakultas Matematika dan Ilmu Pengetahuan Alam \\ Universitas Hasanuddin Makassar \\ *Penulis koresponden. Alamat email: altin@ science.unhas.ac.id
}

\begin{abstract}
Abstrak
Kajian terhadap daerah rawan bencana kegempaan dan tsunami di Kabupaten Bulukumba dilatarbelakangi oleh kondisi struktur geologi dan geomorfologi di daerah tersebut. Keberadaan satuan batuan yang menyusun geomorfologi Bulukumba mempunyai dimensi yang berbeda-beda. Batuan tertua berumur Miosen tengah (Bedrock) berada pada pemekaran dasar laut Teluk Bone sementara batuan termuda berumur Plistosen berada pada sesar Walanae di daratan Bulukumba (Formasi Lompobattang). Hal ini menandakan sistem tektonik yang bekerja tidak selalu sama. Struktur geologi di daerah ini menyebabkan kondisi yang tidak stabil. Ketidakstabilan ini mengancam keberadaan daerah dan masyarakat Bulukumba. Metoda analisis data yang digunakan dalam penelitian adalah deduksi probabilistik dengan pendekatan dedukto-hipotetiko-verifikatif..Data primer diperoleh melalui survei lapangan, sedangkan data sekunder dikumpulkan melalui penelusuran literatur kepustakaan. Analisis data menggunakan analisis statistik sederhana. Berdasarkan perhitungan parameter kewaspadaan diperoleh tingkat pengetahuan kegempaan dan tsunami masyarakat di Kecamatan Rilau Ale, Bulukumba rata-rata bernilai 5,44 berkategori sedang. Tingkat sikap rata-rata bernilai 71,19 berkategori tinggi, sedang tingkat kesiapsiagaan bernilai 49,17 berkategori kurang siap.
\end{abstract}

Kata Kunci: Kegempaan, tsunami, struktur geologi, geomorfologi, analisis statistik.

\begin{abstract}
This study at tsunami and earthquake of the Bulukumba region by considering the geological and geomorphological condition of the area as the background. The geomorphology of Bulukumba region is formed by various lithologies. The oldest rock of Middle Miocene is found at Teluk Bone Sea floor spreading while the newest one of the Plistocene (Lompobattang Formation) is found at Walenae fault (Bulukumba terrain). This fact indicates the existence of different tectonic system in the area. Inevitably, the geological structure causes instability at its region. The instability becomes a serious threat to the peoples of Bulukumba region. The method used for data analysis in this study is the deductiveprobabilistic method with a hipothetic-verificational approch. Two method of data retrieval have been used ie, the field survey of the area (questionnaire method), and the literatures collection. The standard statistical analysis is used to test the data. The calculation of the vigilance parameter has shown that the arverage tsunami and earthquake level of students knowled in the Rilau Ale district is average 54,4 (moderate category). The level of attitude is average 71,19 (high category), while the level of preparedness is worth 49,17 (poorly prepared category).
\end{abstract}

Keywords : Earthquake, Tsunami, geological structure, geomorphology, statistical 


\section{Pendahuluan}

Sejak perkembangan peradaban budaya, manusia telah mengenal apa yang disebut dengan bencanaalam. Dilihat dari kacamata ilmu kebumian, bencanaalam merupakan proses alam kebumian yang berjalan relatif sangat cepat dengan ukuran manusia. Semua ini menyangkut gejala alam yang pada hakekatnya merupakan proses alam yang wajar. Proses alam akan menjadi sebuah bencana alam bilamana proses alam tersebut mengenai semua aktivitas budaya manusia. Apakah aktivitas itu di kota, di desa, di kawasan pegunungan, kawasan pantai, daerah kantong-kantong kemiskinan atau daerah dengan akses ekonomi yang tinggi atau wilayah yang mempunyai aset nasional (Soepaheluwakan, 2006).

Dalam dua dasawarsa terakhir hingga memasuki abad 21 kini, tanpa disadari jumlah manusia, harta benda/aset nasional yang menjadi korban bencanaalam kebumian ternyata meningkat, meskipun dari disiplin ilmu geofisika maupun klimatologi, lingkungan geologi dimasa kini (Kuarter, kurang dari 1.8 juta tahun yang lalu hingga sekarang ini) tidak menunjukkan suatu perubahan yang mendasar. Contohcontoh dibeberapa negara adalah: gempabumi di Peru, gempabumi di Kobe, gempabumi di Meksiko, gempabumi di Iran dan gempabumi di Nepal tahun 2015 (Surono, 2016).

Di dalam negeri beberapa bencana kebumian diantaranya: tsunami di Flores, tsunami di Banyuwangi, Gempabumi di Liwa, gempabumi dan tsunami di Pangandaran dan Cilacap Juli 2006, gempabumi di Nabire, tsunami di Biak, gempabumi di Alor, gempabumi dan tsunami di Aceh dan Sumut; gempabumi Bantul dan Klaten Mei 2006, gempabumi di Mandailing Natal, Sumatera Utara, dan tsunami Mentawai serta awan panas Merapi 2006 dan Oktober-November 2010 (BRG, 2011). Beberapa longsor dan banjir bandang meraimaikan bencana dalam negeri seperti: longsor Gunung Bawakaraeng (Massinai, 2015), banjir Pantai Utara Jawa, banjir di Jakarta, banjir di Aceh dan Sumatera Utara, tanah longsor/banjir bandang di Garut, tanah longsor dan banjir bandang di Bohorok dan di Pacet Jawa Timur, tanah longsor di Banjarnegara, banjir di berbagai tempat di Sumatera, Kalimantan, dan Jawa, banjir bandang Waisor, longsor di Solok. Hal ini merupakan peningkatan yang nyata dari peristiwa bencana kebumian baik ditinjau dari segi kejadiannya maupun jumlah korban manusia yang ditimbulkannya (BRG, 2011).

Kabupaten Bulukumba merupakan daerah yang potensial mengalami bencana kegempaan dan tsunami. Sebelah Timur Bulukumba terdapat zona pemekaran dasar laut Teluk Bone yang berpotensi menimbulkan tsunami. Sedang di daratan Kabupaten Bulukmba terdapat sesar Walenae yang berpotensi menggerakan daratan berupa gempabumi. Hal ini melatarbelakangi penulis untuk melakukan pengabdian masyarakat di Kecamatan Rilau Ale Kabupaten Bulukumba (Massinai, 2015). Model-model struktur geologi di daerah penelitian dapat dilihat pada Gambar 1.

Struktur geologi ini merupakan pemadanan yang ada di atas ataupun di bawah permukaan bumi. Struktur yang ada di permukaan bumi ini merupakan miniatur sesar. Sesar-sesar di permukaan ataupun di bawah permukaan bumi bila bergerak akan menimbulkan gempabumi. Apabila terjadi di laut akan menimbulkan tsunami jika magnitudonya sampai 6, 8 SR atau lebih. Model-model struktur inilah yang akan beguna bagi masyarakat di daerah 
Bulukumba dalam hal memahami fenomena gembapubi dan tsunami.

Penelitian ini bertujuan mengetahui gejala lokasi yang berpeluang besar terjadinya gempa berpotensi tsunami dan menghindarkan masyarakat dari bencana merupakan kebutuhan hidup setiap mahluk karena kedamaian hidup merupakan naluri setiap mahluk. Tujuan lain adalah mengetahui tentang mekanisme terjadinya gempabumi dan tsunami, peranan masyarakat, dalam membentuk kelompok masyarakat yang siaga bencana.

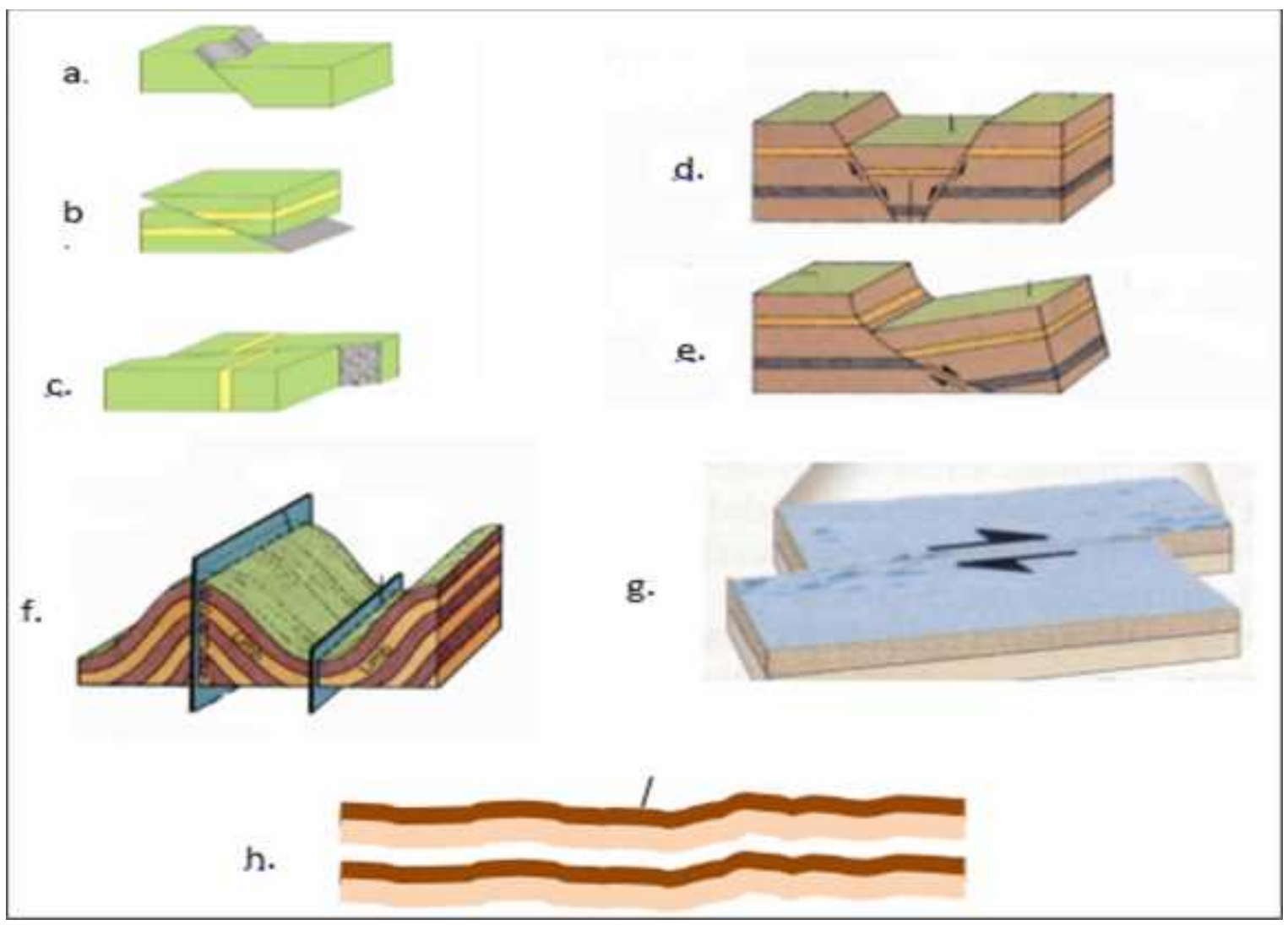

Gambar 1 Model struktur Geologi di Bulukumba, (Barry and Grady, 1987; Massinai, 2015)

Keterangan : a). sesar normal b). sesar naik c). sesar merencong d). graben e). setengah graben f). lipatan g). sesar geser h). stratigrafi

\section{Metode Penelitian}

Adapun bahan yang dibutuhkan

1. Peta Geologi Lembar Bulukumba

2. Peta RBI Lembar Bulukumba

3. Miniatur Struktur Geologi

4. Materi kuesiner.

Analisis data yang diperoleh diolah dengan pendekatan probabilistik yang dilakukan melalui beragam uji statistik. Maksud penggunaan statistik dalam penelitian ini adalah untuk mendapatkan hasil penelitian dengan tingkat kepercayaan tertentu yang berlaku pada disiplin ilmu kebumian. Massinai (2015) menyatakan bahwa pendekatan probabilistik dilakukan dengan cara verifikasi, yaitu pengujian statistik terhadap fenomena sebagai objek penelitian 
untuk memperoleh taraf nyata (alfa) sebagai ukuran kepercayaan.

Teknik pengumpulan data menggunakan instrumen kuesiner. Kuesiner digunakan untuk mengetahui tingkat pengetahuan masyarakat dengan menggunakan 3 indikator kebencanaan, yaitu: pengetahuan tentang gempabumi dan tsunami, sikap masyarakat/masyarakat terhadap gempabumi dan tsunami, dan kesiapsiagaan jika terjadi gempabumi dan tsunami.

Ketiga indikator tersebut mengacu pada indeks tingkat pengetahuan tentang gempabumi, seperti pada tabel berikut,

Tabel 1. Indek Tingkat Pengetahuan Bencana Gempabumi (Sopaheluwakan, 2006)

\begin{tabular}{ccc}
\hline No & $\begin{array}{c}\text { Nilai indeks tingkat } \\
\text { pengetahuan }\end{array}$ & Kategori \\
\hline 1 & $>66,67$ & Tinggi \\
\hline 2 & $33,34-66,66$ & Sedang \\
\hline 3 & $<33,33$ & Rendah \\
\hline
\end{tabular}

Tabel indeks tingkat pengetahuan digunakan untuk menentukan kategori tingkat pengetahuan masyarakat terhadap bencana gempabumi dengan cara mengacu pada indeks yang diperoleh dari hasil kuesioner responden ke dalam tabel indeks tingkat pengetahuan bencana gempabumi. Sikap dan kesiapsiagaan masyarakat mengacu pada Tabel 2. Tabel indeks ini digunakan untuk menentukan kategori sikap dan kesiapsiagaan masyarakat menghadapi bencana kegempaan dan tsunami.

Tabel 2. Indeks Tingkat Sikap Kesiapsiagaan Bencana (Sopaheluwakan, 2006)

\begin{tabular}{ccc}
\hline No & Nilai Indeks & Kategori \\
\hline 1 & $80-100$ & Sangat siap \\
\hline 2 & $65-79$ & Siap \\
\hline 3 & $55-64$ & Hampir Siap \\
\hline 4 & $40-54$ & Kurang siap \\
\hline 5 & $<40$ & Belum Siap \\
\hline
\end{tabular}

Pengukuran-pengukuran tingkat pengetahuan, sikap dan kesiapsiagaan terhadap bencana kegempaan dan tsunami berdasarkan perhitungan indeks menggunkan formula, berikut.

$l_{1}=\frac{\text { skor riil parameter }}{\text { skor maksimum parameter }} \times 100$

\section{Hasil dan Pembahasan}

Kecamatan Rilau Ale, Bulukumba merupakan daerah yang dilalui sesar Walanae yang berpotensi terjadinya gempabumi. Begitu juga dengan Teluk Bone yang berda di sebelah timur Kecamatan Rilau Ale berpotensi menimbulkan tsunami. Dasar laut Teluk Bone merupakan zona pemekaran yang sangat rentang terhadap tsunami. Di wilayah ini terdapat palung sebagai indikasi pemekaran dasar laut tersebut Massinai (2015).

Hasil kuesiner yang diisi masyarakat diperoleh hasil tingkat pengetahuan, sikap, dan kesiapsiagaan masyarakat terhadap kegempaan dan tsunami. Data yang diolah secara faktual dapat dilihat pada Tabel 3, 4 dan 5, berikut.

Tabel 3 memperlihatkan rata-rata pengetahuan Masyarakat di Kecamatan Rialu Ale, Bulukumba bernilai sedang. Tingkat pengetahuan tinggi pada indikator pengertian gempabumi, gempa kuat, fenomena terjadinya gempa dan pengalaman pada saat gempa. Pengalaman pada saat gempa mempunyai arti yang mendalam bagi masyarakat di Kecamatan Rilau Ale, Bulukumba. Kecamatan ini berada pada jalur sesar aktif Walennae. Pada tahun 2015 terjadi gempa di daerah ini dengan kekuatan 4,5 SR. Hal ini menyebabkan indikator pengalaman berkategori tinggi. Tingkat pengetahuan rendah pada prediksi terjadinya 
gempa, ciri bangunan tahan gempa dan rumah tingkat tahan terhadap tsunami. Hal ini terjadi karena daerah ini memang belum pernah terjadi tsunami. Begitu juga prediksi kegempaan, masyarakat belum mengetahuai istilah ini.

Tabel 4 memperlihatkan indikator tingkat sikap masyarakat terhadap kegempaan dan tsunami rata-tinggi tinggi, namun indikator tentang tsunami di daerah ini bernilai rendah. Hal ini dapat dimengerti bahwa sejak 2 abad yang lalu belum ada sejarah terjadinya tsunami di daerah ini. Namun demikian perlu diwaspadai, karena di sebelah timur terdapat Teluk Bone. Pemekaran lantai samudera (spreading) terdapat di dasar laut Teluk Bone. Apabila tektonik di sekitar Pulau Sulawesi bagian selatan bergerak, maka dapat menimbulkan gempa di dasar laut Teluk Bone. Hal ini dapat menimbulkan tsunami.

Tabel 5 memperlihatkan tingkat kesiapsiagaan masyarakat terhadap kegempaan dan tsunami rata-rata kurang siap. Indikator kalau di dalam rumah terjadi gempabumi atau tsunami ini saja yang sangat siap. Masyarakat perempuan yang secara naluri selalu siap menyelamatkan barang-barangnya menjadi faktor sangat siapnya indikator ini. Begitu juga dengan indikator membagi pengetahuan kepada keluarga yang lain bernilai siap.

Objek penelitian pada masyarakat merupakan potensi yang paling baik untuk sosialisasi kewaspadaan terhadap kegempaan dan tsunami. Masyarakat dapat menginformasikan kepada kepada keluarga, tetangga di kampung masing-masing. Suatu gejala di Rilau Ale tahun 2013 lalu tejadi gempabumi yang mengakibatkan banyak masyarakat yang mengalami pusing-pusing dan rumah berantakan.

Kecamatan Rilau Ale Bulukumba kebanyakan penduduknya berpencaharian petani dan perkebunan karet, kelapa sawit, merica dll. Hal ini merupakan objek yang harus disosialisasikan tentang kegempaan dan tsunami. Beberapa lahan perkebunan dan persawahan berada pada gawir-gawir sesar Walanae.

Tabel 3. Tingkat pengetahuan masyarakat terhadap kegempaan dan tsunami

\begin{tabular}{llcc}
\hline No & \multicolumn{1}{c}{ Indikator Pengetahuan } & $\begin{array}{c}\text { Indeks } \\
\text { Pengetahuan }\end{array}$ & $\begin{array}{c}\text { Tingkat } \\
\text { Pengetahuan }\end{array}$ \\
\hline 1 & Pengertian Bencanaalam & 73,8 & Tinggi \\
\hline 2 & Fenomena penyebab bencana & 99,7 & Tinggi \\
\hline 3 & Penyebab gempabumi dan tsunami & 49 & Sedang \\
\hline 4 & Prediksi terjadinya gempabumi & 0 & Rendah \\
\hline 5 & Pengertian gempa kuat & 69,9 & Tinggi \\
\hline 6 & Ciri-ciri bangunan tahan gempa & 28,9 & Rendah \\
\hline 7 & Pengalaman pada saat gempa & 92,7 & Tinggi \\
\hline 8 & Gempa dapat mengakibatkan tsunami & 54,9 & Sedang \\
\hline 9 & Tanda-tanda tsunami & 64,2 & Sedang \\
\hline 10 & Ciri-ciri bangunan tahan tsunami & 38 & Sedang \\
\hline 11 & Rumah bertingkat dengan tsunami & 1,9 & Rendah \\
\hline 12 & Asal pengetahuan gempa dan tsunami & 66,4 & Sedang \\
\hline 13 & Pernakah menularkan pengetahuan & 42,3 & Sedang \\
\hline
\end{tabular}


Tabel 4 Tingkat sikap Masyarakat terhadap kegempaan dan tsunami

\begin{tabular}{|c|c|c|c|}
\hline No & Indikator Sikap & $\begin{array}{l}\text { Indeks } \\
\text { Sikap }\end{array}$ & $\begin{array}{c}\text { Tingkat } \\
\text { Sikap }\end{array}$ \\
\hline 1 & $\begin{array}{l}\text { Apakah perlu adanya antisipasi bencana Tsunami dari } \\
\text { keluarga }\end{array}$ & 96,7 & Tinggi \\
\hline 2 & Apakah daerah ini rawan bencana Tsunami & 4,8 & Rendah \\
\hline 3 & $\begin{array}{l}\text { Apakah perlu menyimpan nomor telephone PLN, } \\
\text { PDAM dan petugas kesehatan terdekat }\end{array}$ & 72,0 & Tinggi \\
\hline 4 & $\begin{array}{l}\text { Apakah perlu Pemantauan perkembangan cuaca oleh } \\
\text { pemerintah }\end{array}$ & 93,1 & Tinggi \\
\hline 5 & $\begin{array}{l}\text { Perlu penyimpanan surat surat penting agar tidak } \\
\text { terkena bencana tsunami }\end{array}$ & 69,8 & Tinggi \\
\hline 6 & $\begin{array}{l}\text { Apakah perlu menyimpan beras, minyak dan makanan } \\
\text { instans sebagai persiapan bila terjadi bencana Tsunami }\end{array}$ & 60,5 & Sedang \\
\hline 7 & $\begin{array}{l}\text { Apakah perlu tentang pentingnya kesiapsiagaan } \\
\text { keluarga dalam menghadapi bencana Tsunami }\end{array}$ & 84,1 & Tinggi \\
\hline 8 & $\begin{array}{l}\text { Apakah perlu kesepakatan keluarga mengenai tempat } \\
\text { evakuasi dalam situasi darurat }\end{array}$ & 55,8 & Sedang \\
\hline 9 & $\begin{array}{l}\text { Apakah perlu kesepakatan keluarga berpartisipasi } \\
\text { dalam simulasi evakuasi }\end{array}$ & 64,9 & Sedang \\
\hline 10 & $\begin{array}{l}\text { Apakah perlu listrik dipadamkan saat pembersihan } \\
\text { rumah pasca bencana Tsunami }\end{array}$ & 68,9 & Tinggi \\
\hline 11 & $\begin{array}{l}\text { Apakah perlu pelatihan pertolongan pertama untuk } \\
\text { anggota keluarga }\end{array}$ & 88,5 & Tinggi \\
\hline 12 & $\begin{array}{l}\text { Apakah perlu pengolahan air bersih setelah terjadinya } \\
\text { bencana Tsunami }\end{array}$ & 78,7 & Tinggi \\
\hline 13 & $\begin{array}{l}\text { Apakah perlu menyiapkan peta evakuasi dan tempat } \\
\text { mengungsi }\end{array}$ & 41,8 & Sedang \\
\hline 14 & $\begin{array}{l}\text { Apakah perlu tentang anakanak sebaiknya tidak boleh } \\
\text { bermain didaerah bencana Tsunami }\end{array}$ & 88,9 & Tinggi \\
\hline 15 & $\begin{array}{l}\text { Apakah perlu membawa kotak P3K dan obat pribadi } \\
\text { ketika mengungsi }\end{array}$ & 93,7 & Tinggi \\
\hline 16 & $\begin{array}{l}\text { Apakah perlu mengungsi bila ada terdengar peringatan } \\
\text { tanda bahaya bencana Tsunami (tsunami drill) }\end{array}$ & 76,8 & Tinggi \\
\hline
\end{tabular}

Tabel 5. Tingkat Kesiapsiagaan masyarakat terhadap kegempaan dan tsunami

\begin{tabular}{clcc}
\hline No & \multicolumn{1}{c}{ Indikator Kesiapsiagaan } & $\begin{array}{c}\text { Indeks } \\
\text { Kesiapsiagaan }\end{array}$ & $\begin{array}{c}\text { Tingkat } \\
\text { Kesiapsiagaan }\end{array}$ \\
\hline 1 & $\begin{array}{l}\text { Dalam mengantisipasi tsunami, sebagai seorang } \\
\text { Masyarakat apakah yang anda lakukan? }\end{array}$ & 50 & Kurang siap \\
\hline 2 & $\begin{array}{l}\text { Seandainya gempa terjadi pada saat dirumah atau } \\
\text { ruangan, apa yang anda lakukan? }\end{array}$ & 80,5 & Sangat siap \\
\hline
\end{tabular}




\begin{tabular}{clcc}
\hline 3 & $\begin{array}{l}\text { Apakah di wilayah tempat anda tinggal terdapat } \\
\text { sistem peringatan bencana tsunami? }\end{array}$ & 45,6 & Kurang siap \\
\hline 4 & $\begin{array}{l}\text { Jika mendengar peringatan tsunami pada saat } \\
\text { diluar, apakah yang anda lakukan? }\end{array}$ & 55 & Hampir siap \\
\hline 5 & $\begin{array}{l}\text { Darimanakah anda memperoleh pengetahuan } \\
\text { terkait kesiapsiagaan bencana terutama di } \\
\text { kalangan masyarakat? }\end{array}$ & 51 & Kurang siap \\
\hline 6 & $\begin{array}{l}\text { Jika pernah mendapatkan pelatihan, workshop } \\
\text { atau seminar tentang pengetahuan bencana, } \\
\text { apakah anda menginformasikan pengetahuan } \\
\text { kesiapsiagaan tersebut kepada anggota keluarga? }\end{array}$ & 73 & Siap \\
\hline
\end{tabular}

\section{Kesimpulan}

1. Wilayah Kecamatan Rilau Ale berada di jalur sesar Walanae sangat berpotensi terjadinya gempabumi $3-5 \mathrm{SR}$.

2. Potensi tsunami di pantai lokasi penelitian sangat besar, dan pengetahuan masyarakat tentang hal ini tidak memadai.

3. Tingkat pengetahuan kegempaan dan tsunami masyarakat di Kecamatan Rilau Ale rata-rata bernilai sedang. Tingkat sikap rata-rata bernilai tinggi, sedang tingkat kesiapsiagaan bernilai kurang siap.

\section{Saran}

1. Dimasa mendatang perlunya ada peta jalur penyelamatan jika terjad gempabumi dan tsunami di Bulukumba.

2. Masyarakat Rialu Ale, Bulukumba perlu diberi sosialisasi kebencanaan yang serius guna penanggulangan bencana gempabumi dan tsunami kalau seketika terjadi.

\section{Daftar Pustaka}

Berry, R.F. and Grady, A.E. 1987. Mesoscopic structures produced by
Plio-Pleistocene wrench faulting in South-Sulawesi, Indonesia. Jour. Struct. Geol. ,V.9, p 563-571.

Billing, M.P., 1972. Structural Geology. NewJersey: Practice-Hall, Englewood Cliff, 606p.

Ismullah, M. F., Lantu, Aswad, S., Massinai, M.A.. 2015. Tectonics earthquake distribution pattern analysis based focal mechanisms (Case study Sulawesi Island, 19932012). AIP Confrence Proceedings, $12 \mathrm{p}$.

Joe, B. and Mark S.. 2006. Independent Appraisal of Ceramic Water Filtration Interventions in Cambodia. University of North Carolina School of Public Health Department of Environmental Sciences and Engineering

Lantu. 2001. Potensi Filter Keramik Gerabah Untuk Penjernihan Air Keruh. Jurnal FUSI Vol.5 No.6 Desember 2001

Massinai, M A., Sudradjat, A., Hirnawan, F., Syafri, I., Hasanuddin., Tahir, M.. I.. 2010. Gerakan Tanah Pada Daerah Rawan Longsor di Das Jeneberang, Bagian Barat Lembah Gunung Bawakaraeng Sulawesi Selatan. Bandung: Jurnal Geologi 
Tata Lingkungan.V 20. No 2. p 93 102.

Massinai, M. A., Sudradjat, dan Lantu. 2013. The Influence ofSeismic Activity in South Sulawesi Area to the Geomorphology of Jeneberang Watershed. International Journal of Engineering and Technology Volume 3 No. 10, p 945 - 948, October, 2013

Massinai, Muh. Altin. 2015. Geomorfologi Tektonik, Jogyakarta: Pustaka Ilmu, $356 \mathrm{p}$.

Paripurno, E.. 2006. Vulkanisme dan Evolusi Tektonik.

Melalui:

<http://bog.com/Geohazard_zone_fil es/ad_files/oasis.html.>. [12/11/2008]

Soepaheluwakan, J. 2006. Kajian Kesiapsiagaan Masyarakat Dalam Mengantisipasi Bencana Gempabumi \& Tsunami. LIPI Jakarta 